3. Labbé RF, Dewanji A. Iron assessment tests: transferrin receptor vis-àvis zinc protoporphyrin. Clin Biochem. 2004;37(3):165-174.

4. Teshome EM, Prentice AM, Demir AY, Andang'o PEA, Verhoef H Diagnostic utility of zinc protoporphyrin to detect iron deficiency in Kenyan preschool children: a community-based survey. BMC Hematol. 2017:17:11

5. Tillyer ML, Tillyer CR. Zinc protoporphyrin assays in patients with alpha and beta thalassaemia trait. J Clin Pathol. 1994;47(3):205-208.

6 Harthoorn-Lasthuizen EJ, Lindemans J, Langenhuijsen MM. Combined use of erythrocyte zinc protoporphyrin and mean corpuscular volume in differentiation of thalassemia from iron deficiency anemia. Eur J Haematol. 1998;60(4):245-251.

7. Park CH, Valore EV, Waring AJ, Ganz T. Hepcidin, a urinary antimicrobial peptide synthesized in the liver. J Biol Chem. 2001;276(11):78067810.

8. Ganz T. Hepcidin and iron regulation, 10 years later. Blood. 2011;117(17):4425-4433

9. Hentze MW, Muckenthaler MU, Galy B, Camaschella C. Two to tango: regulation of mammalian iron metabolism. Cell. 2010;142(1):24-38.

10. Girelli D, Nemeth E, Swinkels DW. Hepcidin in the diagnosis of iron disorders. Blood. 2016;127(23):2809-2813.

11. Kautz L, Jung G, Valore EV, Rivella S, Nemeth E, Ganz T. Identification of erythroferrone as an erythroid regulator of iron metabolism. Nat Genet. 2014;46(7):678-684.

12. Ganz T. Erythropoietic regulators of iron metabolism. Free Radic Biol Med. 2018 Jul 5. [Epub ahead of print]

13. Prentice AM, Doherty CP, Abrams SA, et al. Hepcidin is the major predictor of erythrocyte iron incorporation in anemic African children. Blood. 2012;119(8):1922-1928.

14. Moretti D, Goede JS, Zeder C, et al. Oral iron supplements increase hepcidin and decrease iron absorption from daily or twice-daily doses in iron-depleted young women. Blood. 2015;126(17):19811989.

15. Pasricha SR, Atkinson SH, Armitage AE, et al. Expression of the iron hormone hepcidin distinguishes different types of anemia in African children. Sci Transl Med. 2014;6(235):235re3.

16. Bergamaschi G, Di Sabatino A, Albertini R, et al. Serum hepcidin in inflammatory bowel diseases: biological and clinical significance. Inflamm Bowel Dis. 2013;19(10):2166-2172

17. De Falco L, Silvestri L, Kannengiesser C, et al. Functional and clinical impact of novel TMPRSS6 variants in iron-refractory iron-deficiency anemia patients and genotype-phenotype studies. Hum Mutat. 2014;35(11):1321-1329.

18. Sham RL, Phatak PD, Nemeth E, Ganz T. Hereditary hemochromatosis due to resistance to hepcidin: high hepcidin concentrations in a family with C326S ferroportin mutation. Blood. 2009;114(2):493-494.

19. Weiss G, Goodnough LT. Anemia of chronic disease. N Engl J Med. 2005;352(10):1011-1023.

20. Thomas DW, Hinchliffe RF, Briggs C, et al. Guideline for the laboratory diagnosis of functional iron deficiency. Br J Haematol. 2013;161(5):639648.

21. Kiss JE. Laboratory and genetic assessment of iron deficiency in blood donors. Clin Lab Med. 2015;35(1):73-91.

22. Camaschella C. Iron-deficiency anemia. N Engl J Med. 2015;372 (19):1832-1843.

23. Hempel EV, Bollard ER. The evidence-based evaluation of iron deficiency anemia. Med Clin North Am. 2016;100(5):1065-1075.

24. Skikne BS, Punnonen K, Caldron PH, et al Improved differential diagnosis of anemia of chronic disease and iron deficiency anemia: a prospective multicenter evaluation of soluble transferrin receptor and the sTfR/log ferritin index. Am J Hematol. 2011;86(11):923-927.

\title{
Is DNA a better assay for residual disease in chronic myeloid leukemia?
}

\author{
Jerald Radich \\ Fred Hutchinson Cancer Research Center, Seattle, Washington, USA \\ E-mail: jradich@fhcrc.org
}

doi:10.3324/haematol.2018.205583

$\longrightarrow$ hronic myeloid leukemia (CML) is not a public health menace. Despite its rarity, it has, and continues to be, the guiding path for the concept of genetically informed medicine (here you can choose your own favorite alternative catch phrase: bench to bedside medicine, personalized medicine, precision medicine, etc.). CML was the first disease where a specific chromosomal abnormality, the Philadelphia chromosome, was identified, and the first disease where the genetic underpinnings of this chromosome abnormality were discovered (the juxtaposition of portions of the BCR gene from chromosome 22 to the tyrosine kinase domains from chromosome 9). ${ }^{1}$ This unique $B C R-A B L$ fusion gene drives the pathophysiology of the disease, and thus has led to the remarkable discovery of the tyrosine kinase inhibitors (TKIs), which have fundamentally changed the natural history of the disease. Only decades ago, the lifespan of a chronic phase CML patient was less than seven years while now these patients enjoy a survival roughly that of the normal population., ${ }^{2,3}$

Chronic myeloid leukemia has also been the model of disease monitoring using specific molecular markers. In this case, the $B C R-A B L$ chimeric RNA is used to assess disease burden, and the clinical significance of $B C R-A B L$ levels are so compelling as to drive treatment milestones based on $B C R-A B L$ levels that are codified in European and US CML guidelines. ${ }^{4 \cdot 6}$ Here, too, CML has laid the groundwork for other diseases to use so-called minimal (more recently, "measurable") residual disease (MRD) to drive treatment decisions and measure clinical trial results.

In CML, $B C R-A B L$ is typically measured by testing peripheral blood RNA. RNA is used since the potential breakpoints between $B C R$ and $A B L$ cover many kilobases of DNA sequence, making an easy PCR procedure impossible. Rather, the mRNA species is predictable with only two major splicing variations, making quantitative RTPCR fairly straightforward. After considerable effort (mostly from the Adelaide group), RNA monitoring has been standardized in an International Scale, making the results comparable across more and more labs worldwide. ${ }^{6}$ The test is very sensitive, with levels of disease burden usually quantifiable to levels of four to five magnitudes from the standardized IS baseline (where a 4-log reduction of $B C R-A B L$ on the IS would equal $0.01 \%$ IS, termed MR4)

However, the RNA assay for $B C R-A B L$ is not perfect. RNA is less stable than DNA, and thus is more susceptible to transit times, temperatures, etc. ${ }^{7,8}$ This problem is ameliorated by the use of two control housekeeping genes, but these are subject to the same influences that affect the target gene, and it is perhaps a bit of a leap to 


\section{$B C R$}

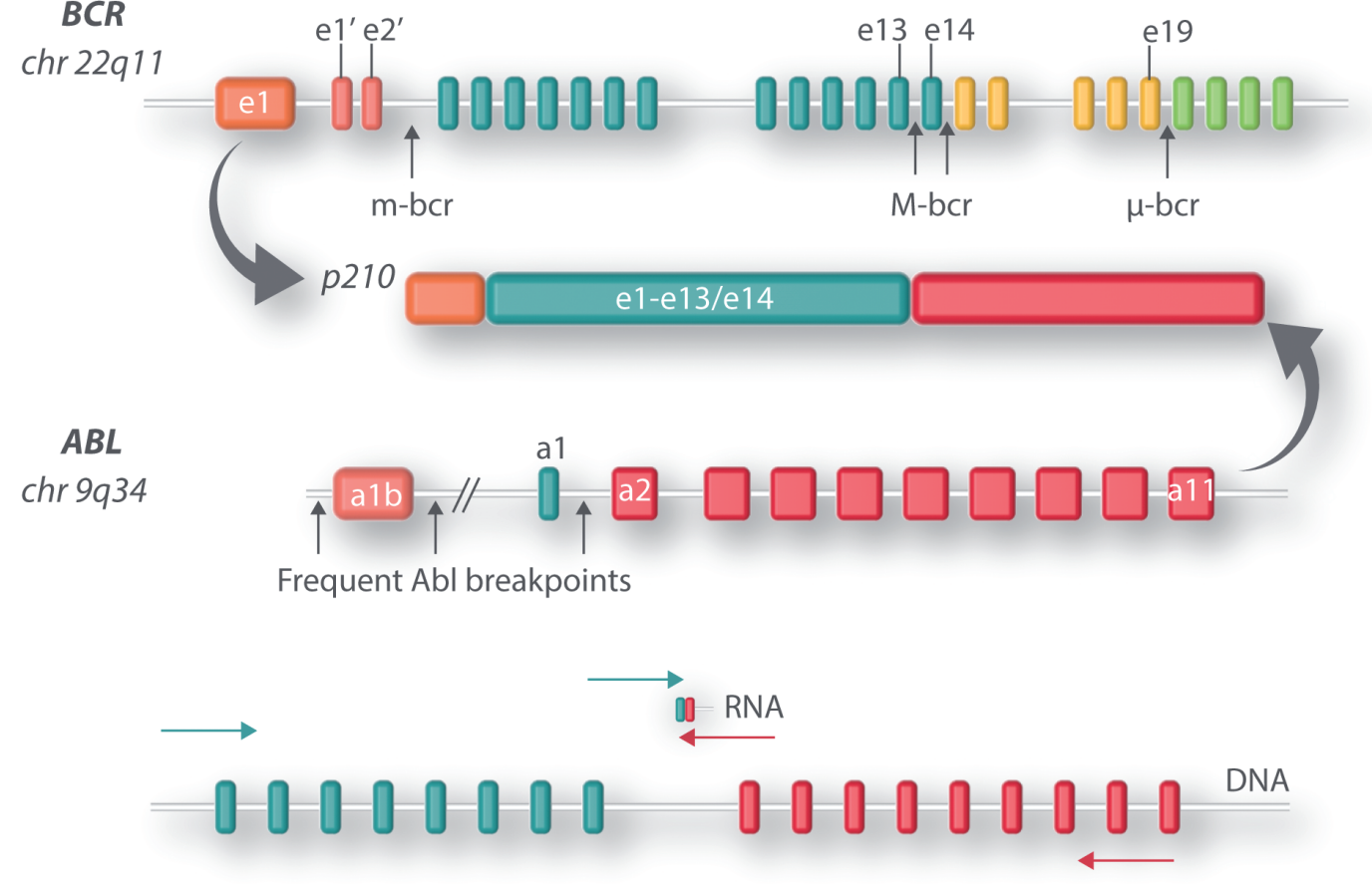

Figure 1. BCR-ABL rearrangement structure. The BCR gene contains three primary breakpoint clusters, the "minor" (m-bcr), “major” (M-bcr), and "micro" ( $\mu$-bcr). Gene rearrangement at the M-bcr site results in either of two p210 fusion chimeric mRNAs, composed of BCR exons 1-13 or exons 1-14 (orange and green) fused to ABL exons 2-11 (red). RT-PCR of BCR-ABL, amplifying only the exons, yields an amplicon product of $\sim 200-300$ bp. However, the genomic breakpoints in BCR and ABL are dispersed over intervals of $3.0 \mathrm{~kb}$ and $150 \mathrm{~kb}$, respectively, making straightforward amplification of the DNA breakpoint impossible. The relative scale of the RNA and theoretical DNA product using the same set of BCR and ABL primers is shown at the bottom of the figure. Thus, for successful DNA amplification, multiple BCR and ABL primers must be used until a successful combination successfully amplifies the breakpoint. After this, sequencing is performed to identify sequences for patient-specific primers and probes.

believe that a series of environmental insults would affect both target and housekeeping genes in the same way. In addition, there are certainly differences in $B C R$ - $A B L$ levels from patient to patient, if not from cell to cell in the same patient. A DNA-based assay would be a more accurate measure of defining the approximate number of actual CML cells in any given patient. (Note that in rare cases a patient can harbor more than one copy of $B C R-A B L$, but this is typically only in cases of advanced phase disease.)

Amplification of the $B C R-A B L D N A$ is difficult, as the potential span of breakpoints within the $B C R$ and $A B L$ genes is vast (Figure 1), as opposed to the limited base pair distance once the chimeric BCR-ABL mRNA is assembled. ${ }^{9,10}$ To perform the DNA-based assay for $B C R$ $A B L$, an initial PCR uses multiple primer sets to first identify the possible DNA breakpoint. Once the sequence of the breakpoint is identified, patient-specific primers are constructed to make a very sensitive assay. Since the patient-specific PCR will have different kinetics from patient to patient, the drop in the disease burden must be measured against the patient's diagnostic disease burden value. This is a very similar concept to following $M R D$ in patients with acute lymphoblastic leukemia, where patient-specific IgVDJ or TCR rearrangements must be amplified with consensus primers, then patient-specific primers and probes developed for each unique assay. [This complexity led to the development of sensitive flow cytometry and next generation sequencing (NGS) methods, the latter discussed below.]
The potential value of a sensitive DNA test is at least 2fold. First, one could study the differences in RNA versus DNA load, correlating this with disease response. Secondly, a DNA assay would allow the detection of CML in cases in which the RNA assay of $B C R-A B L$ is undetectable. This would be especially interesting in the case of discontinuation in CML, where some patients with a prolonged deep molecular response stop TKI treatment and do not relapse. ${ }^{11,12}$ Are those cases that quickly relapse after discontinuation simply those in whom the disease is at a higher burden, though undetectable by RNA assays? Could patients who have no MRD by RNA or DNA assays be the lucky patients for whom discontinuation will be successful? 13 $^{13}$

In this issue of the Journal, the Adelaide group expands on their previous studies of DNA-based $B C R-A B L$ detection and show the potential of this assay to probe basic disease and clinical issues. ${ }^{14}$ They studied 59 patients with 516 samples on which RNA and DNA assessments of disease burden were performed. Several important findings were found.

First, they found that, early in disease treatment, the number of copies of RNA was generally higher than the DNA (roughly 2-fold) whereas after around six months, RNA and DNA levels were fairly similar. The biological reason for this is unclear. However, the kinetic decay of BCR-ABL with TKI therapy shows a multi-order decay, with an initial decline, followed by a slower decay. These two findings combined suggest that, at diagnosis, a pop- 
ulation of committed progenitors, making a fair amount of $B C R-A B L$ RNA (and protein), die quickly, followed by a population of cells less active with regards to $B C R-A B L$ production.

Second, the BCR-ABL decline appears to be more significant in the case of patients with the b14a2 transcript, rather than the shorter b13a2 transcript. This has been seen before in other studies. ${ }^{15,16}$ The reason is unclear, but the speculation is that the exon responsible for the longer version is immunogenetic. CML is well-known to be unusually susceptible to immune-mediated attack (note the effects of interferon, allogeneic transplant, and donor lymphocyte infusions), and the current speculation is that this is another manifestation of this effect. ${ }^{17}$ If so, we might expect the b14a2 cases to also enjoy more success with discontinuation.

Third, in multiple cases, DNA detected residual disease whereas RNA did not. Thus, in 86 cases where $B C R-A B L$ was undetected by RNA, the DNA assay found disease in $42(49 \%)$. Moreover, the median level of detectable disease after 12 months of therapy was higher by DNA than by RNA.

Where will this lead? First, one could imagine the study of colonial heterogeneity. It is becoming clear that in many diseases (e.g. acute myeloid leukemia) there are multiple related clones at diagnosis, and treatment may cause a Darwinian selection of resistance. Since resistance is less common in CML in the TKI era, and since our tools of defining disease are insensitive to measuring the subtle difference (the $\mathrm{Ph}$ and $B C R-A B L \mathrm{RNA}$ ), DNA-based assays that identify different unique $B C R$ and $A B L$ breakpoints may be able to eventually detect multiple clones. Moreover, DNA-based assays may help distinguish those patients who can and those who should not undergo discontinuation. It may be especially interesting to study cases who have $B C R-A B L$ by DNA but do not subsequently relapse after TKI is discontinued. Is this evidence of immunological control of residual CML? Is this assay detecting $B C R-A B L D N A$ in lymphocytes that may not be involved in the disease process or relapse?

In order to do some of these things, better assays will be needed. The advent of single cell technologies that can perform either genotyping and transcription analysis also need to be developed, and the search for techniques that might allow both to be performed is ongoing. ${ }^{12}$ This could allow for studies of biology, heterogeneity, and response. Assay methods to quickly genotype complex DNA rearrangement structures are now FDA approved to study immunoglobulin gene rearrangements for MRD in lymphoid malignancies, and the same approach could be used to streamline the DNA approach in CML. New sequencing methods can detect single base pair differences at a one in a million resolution, approximately $3-4$ orders of magnitude better than NGS. ${ }^{19}$

Believers in the theory of the "RNA world" suggest that RNA was the key to life's first steps from primordial ooze to cellular creatures (alas, some have made it farther than others).$^{20}$ DNA followed as a more durable way to collect and store information. Perhaps the same evolutionary order is on tap for those researchers interested in the clinical importance of molecular diagnostics in CML.

\section{References}

1. Rowley JD. A new consistent chromosome abnormality in chronic myelogenous leukemia identified by quinacrine fluorescence and Giemsa staining. Nature. 1973;243(5405):209-213.

2. Druker BJ, Guilhot F, O'Brien SG, et al. Five-year follow-up of patients receiving imatinib for chronic myeloid leukemia. $N$ Engl J Med. 2006;355(23):2408-2417.

3. Huang X, Cortes J, Kantarjian H. Estimations of the increasing prevalence and plateau prevalence of chronic myeloid leukemia in the era of tyrosine kinase inhibitor therapy. Cancer. 2012;118(12):3123-3127.

4. Hughes TP, Kaeda J, Branford S, et al. Frequency of major molecular responses to imatinib or interferon alfa plus cytarabine in newly diagnosed chronic myeloid leukemia. N Engl J Med. 2003;349(15):14231432

5. Hanfstein B, Muller MC, Hehlmann R, et al. Early molecular and cytogenetic response is predictive for long-term progression-free and overall survival in chronic myeloid leukemia (CML). Leukemia. 2012;26(9):2096-2102.

6. Hughes T, Deininger M, Hochhaus A, et al. Monitoring CML patients responding to treatment with tyrosine kinase inhibitors: review and recommendations for harmonizing current methodology for detecting $\mathrm{BCR}-\mathrm{ABL}$ transcripts and kinase domain mutations and for expressing results. Blood. 2006;108(1):28-37.

7. Radich JP, Mao M, Stepaniants S, et al. Individual-specific variation of gene expression in peripheral blood leukocytes. Genomics. 2004;83(6):980-988.

8. Dvinge $H$, Ries R, Ilagan J, Stirewalt DL, Meshinchi S, Bradley RK. Sample processing obscures cancer-specific alterations in leukemic transcriptomes. PNAS. 2014;111(47):16802-16807.

9. Ross DM, O'Hely M, Bartley PA, et al. Distribution of genomic breakpoints in chronic myeloid leukemia: analysis of 308 patients. Leukemia. 2013;27(10):2105-2107.

10. Linhartova J, Hovorkova L, Soverini S, et al. Characterization of 46 patient-specific BCR-ABL1 fusions and detection of SNPs upstream and downstream the breakpoints in chronic myeloid leukemia using next generation sequencing. Mol Cancer. 2015;14:89.

11. Mahon FX, Réa D, Guilhot J, et al. Discontinuation of imatinib in patients with chronic myeloid leukaemia who have maintained complete molecular remission for at least 2 years: the prospective, multicentre Stop Imatinib (STIM) trial. Lancet Oncol. 2010;11(11):1029-1035.

12. Hughes TP, Ross DM. Moving treatment-free remission into mainstream clinical practice in CML. Blood. 2016;128(1):17-23.

13. Ross DM, Branford S, Seymour JF, et al. Patients with chronic myeloid leukemia who maintain a complete molecular response after stopping imatinib treatment have evidence of persistent leukemia by DNA PCR. Leukemia. 2010;24(10):1719-1724

14. Pagani IS, Dang P, Kommers IO, et al. BCR-ABL1 genomic DNA PCR response kinetics during first-line imatinib treatment of chronic myeloid leukemia. Haematologica. 2018;103(12):2026-2032.

15. Jain P, Kantarjian H, Patel KP, et al. Impact of BCR-ABL transcript type on outcome in patients with chronic-phase CML treated with tyrosine kinase inhibitors. Blood. 2016;127(10):1269-1275.

16. Lucas CM, Harris RJ, Giannoudis A, et al. Chronic myeloid leukemia patients with the e13a2 BCR-ABL fusion transcript have inferior responses to imatinib compared to patients with the e14a2 transcript. Haematologica. 2009;94(10):1362-1367.

17. Clark RE, Dodi IA, Hill SC, et al. Direct evidence that leukemic cells present HLA-associated immunogenic peptides derived from the BCRABL b3a2 fusion protein. Blood. 2001;98(10):2887-2893.

18. Zheng GXY, Terry JM, Belgrader P, et al. Massively parallel digital transcriptional profiling of single cells. Nat Commun. 2017;8:14049.

19. Wu D, Emerson RO, Sherwood A, et al. Detection of minimal residual disease in $B$ lymphoblastic leukemia by high-throughput sequencing of IGH. Clin Cancer Res. 2014;20(17):4540-4548.

20. Neveu M, Kim HJ, Benner SA. "The "strong" RNA world hypothesis: fifty years old". Astrobiology. 2013;13(4):391-403. 